\title{
Integration of Life Cycle Data in a BIM Object Library to Support Green and Digital Public Procurements
}

\author{
Ambra Barbini ${ }^{1,2 *}$, Giada Malacarne ${ }^{1}$, Katrien Romagnoli ${ }^{1}$, Giovanna A. Massari ${ }^{2}$, Dominik T. Matt ${ }^{1,3}$ \\ ${ }^{1}$ Process Engineering in Construction, Fraunhofer Italia Research, Bolzano 39100, Italy \\ ${ }^{2}$ Civil, Environmental and Mechanic Engineering, University of Trento, Trento 38123, Italy \\ ${ }^{3}$ Industrial Engineering and Automation, Free University of Bolzano, Bolzano 39100, Italy
}

Corresponding Author Email: ambra.barbini@ fraunhofer.it

https://doi.org/10.18280/ijsdp.150702

Received: 29 January 2020

Accepted: 15 September 2020

\section{Keywords:}

BIM objects, building products, Green

Public Procurement, LCA, LCC, life

cycle, sustainable design

\begin{abstract}
To reduce the environmental and economic impacts of the construction sector it is essential to follow sustainable models in each stage of the design process, including the procurement phase. Construction costs are generally calculated at this stage, overlooking life-cycle impacts. Since 2016, the Italian code of public procurement requests to comply with environmental minimum criteria and introduced the mandatory use of digital methods and tools. Given the opportunity to exchange information through BIM objects, this research explores the possibility to manage environmental and economic data with digital methods and tools in public procurement. This paper presents an evaluation system and a workflow to support the decision makers in considering the life cycle of a construction, optimizing environmental and economic impacts. The evaluation system developed is based on parameters, focused on environmental and economic impacts. Parameters have been collected analyzing and comparing sustainability norms and protocols. Results show that the developed system not only can support a public body during the procurement phase, but also delivers a database for further project phases, such as operation and end of life.
\end{abstract}

\section{INTRODUCTION}

The building sector consumes up to $40 \%$ of the extracted raw materials [1]. In 2014, it demanded up to $40 \%$ of global energy and was responsible for $50 \%$ of the greenhouse gasses [2]. Therefore, it is crucial to be aware of environmental impacts of buildings from design to end-of life. Following the general trend in society, sustainability is increasingly considered in the building sector as well, leading to the development of several rating systems for the evaluation of sustainable design, such as LEED or ARCA [3]. These systems generally include a specific section about resources and materials. These sections evaluate the quality of construction products considering their environmental impacts [4]. In this way, sustainability issues are even more crucial when selecting the products for a construction project.

In public works, the selection of construction products happens during the procurement phase. This is a crucial phase in the project's life cycle as the definition of cost and the selection of contractors occurs [5]. Even though public procurement can follow several principles, according to the project features and the contract specificities, the offer cost is generally a key aspect. However, the raising concerns for climate resilient buildings are expected to reinforce the requirements for novel decision-making paradigms in building structures that will augment the traditional engineering performance indexes: cost, safety and buildability, with sustainable aspects: energy use, resources depletion, emissions and waste [6]. Recent studies reject the traditional idea that development is a synonym for economic growth, proposing a paradigm that includes fundamental ethical values and introducing the idea of Green Public Procurement (GPP) [7].

In this regard, the Italian government introduced the minimum environmental criteria (CAM, the Italian abbreviation), mandatory for every potential contractor. The CAM have the purpose of supporting the procurement of sustainable products and technologies and concern the origin of resources, production processes and end-of-life alternatives. At the European level there is a growing share of initiatives that aim to stimulate the implementation of environmental impact assessment (EIA) tools into everyday design and construction practice (e.g. Roadmap to resource efficient Europe, Circular Economy Action Plan). Considering these aspects, the attention is not only focused on a specific phase but is extended to the whole life cycle of the project and its components.

The analysis of the project's lifecycle at an early stage helps to increase the awareness of decision makers on both environmental and economic impacts [8]. These impacts can be measured applying dedicated methods, like Life Cycle Assessment (LCA) and Life Cycle Costing (LCC). The outcomes of these assessments can also support decision makers in excluding solutions that will have negative impacts during the life cycle, for example, due to harmful consequences for the environment or high maintenance costs.

However, LCA and LCC are based on a significant amount of data, considering both inputs needed to perform the assessments and outcomes, helpful to perform further analysis and evaluations.

As database and data analysis tool, Building Information 
Modeling (BIM) can support the process of collecting and managing all this information. Existing experiences already show that BIM is suitable for sustainable building design, for examples in performing energy modelling, sustainable materials and management of site and logistics [9]. Moreover, given the opportunity for a public body to exchange information with the project partner through BIM objects [10], this paper aims to integrate life cycle aspects into a previously developed BIM objects library. The purpose is to support the adoption of sustainable products in public projects, considering the procurement as the key phase to evaluate and compare environmental and economic impacts of building products, within an approach oriented to life cycle awareness. Therefore, rating systems, CAM and BIM norms have been analyzed and compared to define groups of parameters that can support an evaluation system, based on the integration of life cycle data within BIM objects.

\section{STATE OF THE ART}

\subsection{Life cycle and the building sector}

Originally life cycle assessment was mainly applied in the industrial sector, to optimize production processes and to prevent waste of materials and/or energy, avoiding shifting the problem from one stage to another, but studying the entire process as a whole [11]. Recently LCA has been applied to building projects, increasing the awareness about building environmental impacts. In addition, more and more countries are developing Environmental Impact Assessment (EIA) tools using Life Cycle Assessment (LCA), since it is the only internationally standardized method and is widely employed [12]. According to Asdrubaldi et al., among the available procedures and tools for Environmental Performance Evaluation (EPE), the LCA is the most complete one, because considers: (i) the entire life cycle of a system, (ii) all the possible environmental impacts, (iii) the environmental effects of the aggregation of possible impacts, to give support to decision makers [13]. Conscious of the inherit constraints of LCA methods and of individual peculiarities of each case study, Buyle et al. [14] highlighted some common trends. In standard buildings, due to heating and/or cooling system, the Operation and Maintenance (O\&M) phase is responsible for up to $90 \%$ of the total environmental burden. In this regard, energy saving policies are bringing more energy efficient solutions for both new and existing buildings [15]. Therefore, other phases of the project lifecycle deserve more attention, i.e. construction and end-of-life phases. According to the LCA results of Ortiz-Rodriguez et al. [16], for example, the production of building materials embodied about $97 \%$ of the construction phase.

LCA is defined in the UNI 14040:2006 as the quantification of environmental impacts, considering the inputs and outputs of materials and energy in each stage of the life cycle. The procedure to quantify these impacts is described in detail in the UNI 14044:2006. An LCA analysis focus on three main stages of the manufacturing process: (i) upstream, related to resource supply, (ii) core-stream, related to the resource transformation and production processes and (iii) downstream, related to products use and end of life. Typically, an LCA has the purpose of predicting the embedded and operative impacts of a project during its life cycle, as well as an LCC aims to forecast the global cost of a project including O\&M and dismantling costs. LCC is a tool that allows to compare cost items and to identify the most effective solution between different alternatives. LCC calculation methods are described in the UNI 16627:2015.

\subsection{BIM and life cycle data}

The integration of BIM and life cycle data has been studied in several researches following different approaches. Röck et al. [17] proposed an early stage project guidance based on performing LCA to different design solutions and comparing the results through BIM conceptual models. Najjar et al. [18] used the application Tally to integrate BIM and LCA. After reviewing the three approaches for the integration of BIM with LCA and LCC, i.e.:

1. use of several software to conduct LCA and LCC, e.g. SimaPro, CostLab, Excel, etc.,

2. connection of a BIM model generated quantity to an LCA and/or LCC database,

3. integration of LCA and LCC data directly in the BIM model,

Santos et al. [19] explored the possibility to include LCA and LCC data in a BIM model to perform further environmental and economic assessments. The optimization of environmental and economic performance of a product is defined as eco-efficiency [20]. According to the World Business Council for Sustainable Development (WBCSD), eco-efficiency is defined as "being achieved by the delivery of competitively priced goods and services that satisfy human needs and bring quality of life, while progressively reducing ecological impacts and resources intensity throughout the life cycle" [21]

\subsection{Green Public Procurements (GPP)}

Pursuing the logic of eco-efficiency principles, the introduction of GPP represents an important opportunity for considering environmental impacts connected to a product's life cycle. According to the European Commission, GPP plays a key role in the EU's efforts to pursuit a more resourceefficient economy. According to Parikka-Alhola [22], GPP can emerge as a powerful way to promote the design of environmentally conscious products and motivate manufacturers to reduce environmental impacts. GPP criteria need to be based on a life-cycle approach and scientific evidence base [23]. In this regard, northern European researches [24, 25] tested possible strategies to convert environmental impact categories' outcomes of an LCA into an environmental impacts cost. This cost is determined by multiplying each impact category with its unit cost and summing the outcomes. The result allows for comparison between product alternatives and can be integrated in LCC considerations

\subsection{Digital public procurements}

Within the context of GPP, this research considers the possibility to collect and manage life cycle data of building products with digital methods and tools, such as datasheets and BIM objects. A previous study on the implementation of BIM in public procurement was carried out in 2013 by Bolpagni [5], who illustrated the possibilities of using a model checker for project design evaluations. In this research, a digital evaluation system based on life cycle information has been developed, 
incorporating LCA and LCC data into BIM objects to highlight sustainable solutions during the earliest project phase. The purpose is to identify groups of parameters that could support public bodies in comparing procurement offers considering environmental and economic impacts and to define and test a possible workflow for a digital evaluation.

\section{RESEARCH METHOD AND TOOLS}

The development of the BIM object library containing LCA and LCC data is based on a real-life case study. The library contains urban furniture items belonging to the corporate design of an Italian public administration, who decided to create this BIM library as a support element for its main activities: design, procurement and facility management.

To implement digital tools in the procurement phase, this research suggests a specific workflow to complete previously modelled BIM objects with products related data and to compare contractor proposals, considering life cycle impacts.

\subsection{Research tools}

The development of this research required to analyze and compare sector-specific norms and the section about "resources and materials" of some selected building rating systems.

Within the international regulatory framework, the international standards related to BIM (Figure 1) and life cycle (Figure 2) supported this study. Parts 3 and 5 of UNI 11337 resulted to be significant for this research, because they both refers to information connected to Building Information Models: part 3 provides templates for data collection of building products, including a section about environmental impacts, part 5 supports the comprehension of information flows.

The life cycle norms analyzed can be grouped into three sets (Figure 2). The norms related to LCA explain the fundamental stages of the assessment and the meaning of the outcomes in terms of environmental impacts. The norms on environmental labels and declarations clarify the process behind each label: type I is awarded by a third certification body, after proving the compliance of specific requirements, type II can be selfdeclared and type III is assigned by a third party, considering the results of an LCA. The UNI EN 16627 (2015) illustrates the calculation methods of LCC, to evaluate the economic performances.

The selected rating systems are LEED [26], recognised and adopted at an international level, DGNB (Deutsche Gesellschaft für Nachhaltiges Bauen) [27], mainly applied in Germany and ARCA [28], common in the northern Italy and focused on wooden products and buildings. The proposed workflow is based on the combined use of three digital tools: (i) MS Excel to create the evaluation system, which links a number of information (proposal value, reference and valid values, unit, score range, score formulas and invalid proposal formulas) to a specific life cycle parameter (Figure 3), (ii) Autodesk Revit, to develop the BIM objects library, which provides proposal value to life cycle parameters into the evaluation system and (iii) Dynamo, to assure data exchange between MS Excel and Revit.

\subsection{Developed evaluation system}

The development of the evaluation system consisted of three main phases:

1. Definition of life cycle parameters, units and scores

2. Identification of reference and valid values

3. Definition of the score formulas to calculate the impact of each parameter.

All the selected information has been collected in an MS Excel datasheet (Figure 3). Within the datasheet, there are eight columns: column A contains the parameters, columns B, $\mathrm{C}$ and $\mathrm{D}$ collect respectively proposal, reference and valid values, column E illustrates the unit of each parameter and column $\mathrm{F}$ the score range achievable, the last two columns $(\mathrm{G}$ and $\mathrm{H}$ ) collect two formulas. The first formula automatically calculates a score or a cost for each parameter upon insertion of the proposal value by the contractor. The second formula highlights the presence of an invalid value in the proposal. At the end of the score formulas column, there is a total environmental score cell (the higher value the better) and a total cost cell (the lower value the better), where all the scores and the costs connected to the life cycle are summed.

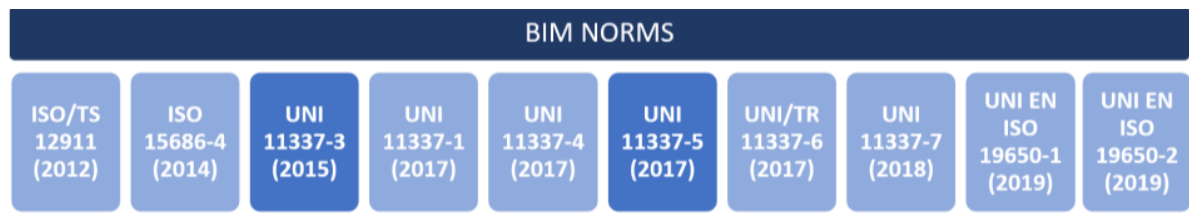

Figure 1. National and International standards about BIM

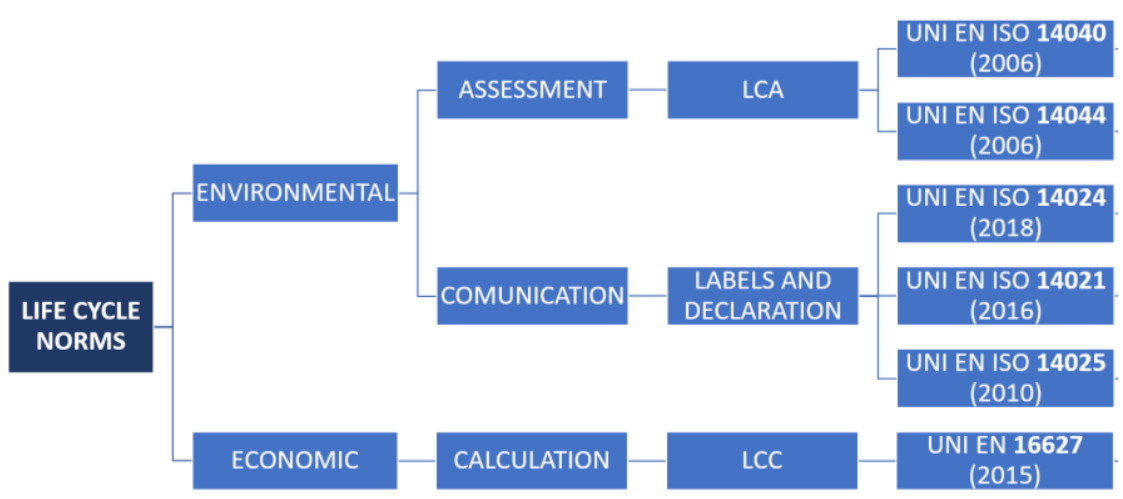

Figure 2. National and International standards connected to life cycle impacts 


\begin{tabular}{|c|c|c|c|c|c|c|c|c|}
\hline 4 & A & B & $\mathrm{C}$ & D & $\mathrm{E}$ & $\mathrm{F}$ & G & $\mathrm{H}$ \\
\hline 1 & Parameter & Proposal value & Reference value & Valid value & Unit & Score & Score formula & Invalid proposal \\
\hline 2 & Distance between production and building sites & & $<150$ & $<1050$ & $\mathrm{~km}$ & $0-2$ & $=\left((150-82)^{*} 2\right) /\left((150-100)^{*} 3\right)$ & $=\mid \mathrm{F}(\mathrm{B} 2>1050)$ \\
\hline 3 & Disassemblable components & & yes & yes/no & - & $0 / 2$ & $=\mid F(B 3=" y e s " ; 2 ; 0)$ & - \\
\hline 4 & Phase 1 & & \multicolumn{2}{|c|}{ Phase 2} & \multicolumn{2}{|c|}{ Phase 1} & \multicolumn{2}{|l|}{ Phase 3} \\
\hline
\end{tabular}

Figure 3. Example of a datasheet organization

\subsubsection{Definition of parameters, units, scores}

As a first step, the identification of significant economic and environmental life cycle impact parameters was performed. Economic parameters have been selected with the public body during dedicated workshops. Environmental parameters, their respective measure units and possible scores emerged comparing:

- the three selected certification systems (LEED, DGNB and ARCA),

- the UNI 11337-3,

- the environmental parameters requested by the Italian CAM.

\subsubsection{Identification of reference and valid values}

The case study refers to three different materials: steel, aluminium and wood for outdoor furniture. Considering the parameters determined in the first phase, reference and valid values for each material have been searched. The purpose is to compare proposal values not only with other possible contractors' values, but also with benchmarks or thresholds.

For each material, the authors researched available certification systems and studied the possible life cycle. Further analysis also investigated resources origin, manufacturing processes, presence of production plants close to the project site and alternative end of life solutions [29-31]. All this information contributed to define reference and valid values for most of the selected parameters. The definition of reference values for the LCA impact categories, as described in the UNI/TS 11337-3, appeared to be particularly complex, due to the lack of benchmarks, and the absence of EPD (Environmental Product Declarations) or LCA of products, like those included in the case study.

\subsubsection{Definition of the score formulas}

For some parameters, the authors defined a score range and the final score is proportionally dependent on the proposal value and automatically calculated in MS Excel. For other parameters, the public body is requested to establish a score, after considering the additional documents, i.e. labels, declarations and certificates. Parameters regarding costs do not receive a score, but a cost value is calculated summing up all the costs to sustain along a defined lifetime. Also, environmental parameters, selected from UNI 11337-3, do not receive scores but a cost value is calculated according to the MMG method, a monetization approach proposed by CEN (European Committee for Standardization) in 2017 [23]. Table 1 provides an extract of values from the MMG method. Moreover, aware of the assumptions regarding LCA results weighting [32], the authors opted for applying an approach that assigns different impact weight to each category of parameters expressing the relative importance of impact categories in monetary values. These factors support not only comparing LCA impact categories, but also in assessing the total cost of products' environmental impacts.

\subsection{Comparison of the environmental impact categories}

Due to a lack of available data, it was not possible to test the entire evaluation system, but only the specific section about environmental impacts listed in Table 1. To perform the tests, the authors used the LCA outcomes obtained by the Ecoinvent database for steel, aluminum and wood generic products. The considered impacts result from an upstream LCA. The database performed the LCA according to the CML method (Centre for Environmental Sciences Leiden, Dutch: Centrum voor Milieukunde Leiden, i.e.), requested by Product Category Rules (PCR) for the release of EPD. The authors considered specifically three reference products for each material and performed the monetization of the impact categories according to the 2017 update of West-European central values for the CEN indicators of the MMG method reported in the third column of Table 1 .

Table 1. Financial conversion factor for each environmental impact category, according to the MMG method

\begin{tabular}{|c|c|c|}
\hline Enviromental impact & Measure unit & $€ /$ unit \\
\hline GWP (Global Warming Potential) & $\mathrm{kg} \mathrm{CO}^{2} \mathrm{eq}$ & 0.05 \\
\hline ODP (Ozone Depletation Potential) & $\mathrm{kg} \mathrm{CFC}-11 \mathrm{eq}$ & 49.10 \\
\hline AP (Acidification Potential) & $\mathrm{kg} \mathrm{SO} 2 \mathrm{eq}$ & 0.43 \\
\hline EP (Eutrophication Potential) & $\mathrm{kg}\left(\mathrm{PO}_{4}\right)^{3} \mathrm{eq}$ & 20.00 \\
\hline $\begin{array}{c}\text { POCP (Photochemical Ozone Creation } \\
\text { Potential) }\end{array}$ & $\mathrm{kg} \mathrm{C} 2 \mathrm{H} 4 \mathrm{eq}$ & 0.48 \\
\hline $\begin{array}{c}\text { ADP (Abiotic Depletation Potential) - } \\
\text { elements }\end{array}$ & $\mathrm{kg} \mathrm{Sb}$ eq & 1.56 \\
\hline $\begin{array}{l}\text { ADP (Abiotic Depletation Potential) - } \\
\text { fossil fuels }\end{array}$ & MJ & 0.00 \\
\hline
\end{tabular}

\subsection{Proposed workflow}

The workflow (Figure 4) for this evaluation system includes five steps:

1. the contractors receive the BIM objects as geometric model reference in IFC format and a datasheet containing parameters, reference and valid values, units and scores,

2. the contractors complete the datasheet with their proposal values and supply the additional documents, to let the public body to evaluate their offers.

3. the proposal values of all the contractors are copied within an electronic sheet, that automatically calculates the environmental/economic score for each proposal value,

4. the public body selects the contractor, considering the total environmental score, the total cost and the additional documents,

5. the information of the selected contractor is incorporated into the BIM objects, through a Dynamo script that transfers parameters and values from Excel to Revit. 


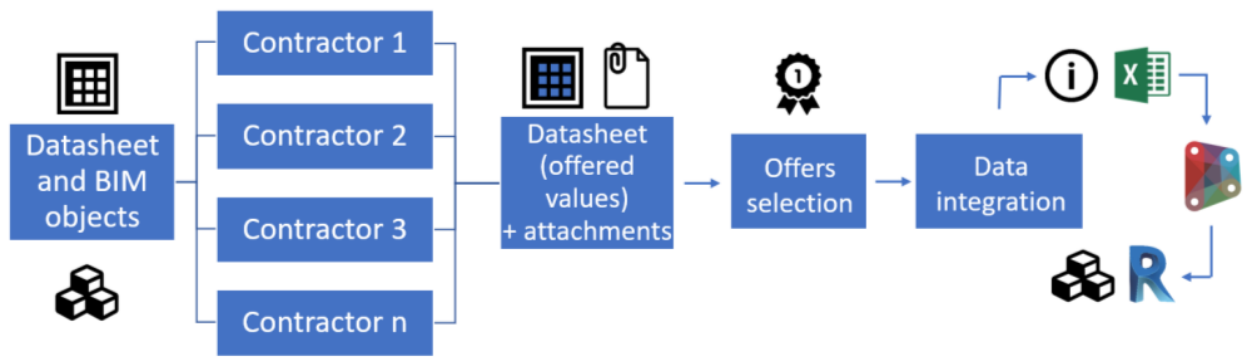

Figure 4. Workflow of the evaluation process

\section{RESULTS}

In the results section, the developed evaluation system is presented. Subsequently the results of the tests performed on the environmental impact section are described.

\subsection{Evaluation system}

The evaluation system consists of seven groups of parameters and for each group there is a list of parameters and scores. Parameters with the symbol * require additional documents to be evaluated. Each group is described below.

\subsubsection{Products origin}

The products origin group (Table 2) aims to promote environmentally conscious value chains. The last three parameters concern the presence of reused, recycled, or rapidly renewable materials and their score is linearly linked to the fraction present in the product or material. The score differences between reused and recycled material is ascribed to the major amount of energy requested by recycling processes. Rapidly renewable materials are preferred to nonrenewable resources but receive a lower score than recycled and reused materials, as assessed by LEEDv3 protocol.

Table 2. Products origin parameters

\begin{tabular}{ccc}
\hline Products origin & Value type & Score \\
\hline Certificate of origin materials available* & yes/no & $0 / 1$ \\
EPD of input material available* & yes/no & $0 / 2$ \\
LCA of input material available* & yes/no & $0 / 1$ \\
Carbon Footprint of input material & yes/no & $0 / 0,5$ \\
available* & $\%$ mass & $0-3$ \\
Reused material \% & $\%$ mass & $0-2$ \\
Recycled material \% & $\%$ mass & $0-1$ \\
\hline Rapidly renewable material \%
\end{tabular}

\subsubsection{Transportation}

This section (Table 3) aims to draw attention to the distances between the production site and the construction site and to promote transportation vehicles with low environmental impacts.

Table 3. Transportation parameters

\begin{tabular}{ccc}
\hline Transportation & Value type & Score \\
\hline Distance production plant - project site & distance & $0-2$ \\
Transportation vehicle & vehicle size & $0-3$ \\
\hline
\end{tabular}

\subsubsection{End of life}

Choosing reusable or recyclable products during the design phase will have a significant impact on the environment and cost during the dismission phase. In this case, a different score is given because of the same reasons as for the material origin section. The possibility to disassemble the components is assessed with two points to privilege products that allow an appropriate dismission of each material (Table 4).

Table 4. End of life parameters

\begin{tabular}{ccc}
\hline End of life & Value type & Score \\
\hline Possibility to disassemble components & yes/no & $0 / 2$ \\
Reusable components \% & $\%$ mass & $0-2$ \\
Recyclable components \% & $\%$ mass & $0-1$ \\
\hline
\end{tabular}

\subsubsection{Environmental assessments}

This section aims to reward the different possible assessments (Table 5). An LCA can refer to different phases: resources supply (upstream), transformation processes (core stream), use and end of life (downstream). The score system allows to collect three points with an entire LCA or less points with only one or two phases evaluated.

Table 5. Environmental assessment parameters

\begin{tabular}{ccc}
\hline Assessments & Value type & Score \\
\hline Upstream LCA (cradle) $^{1}$ & yes/no & $0 / 1$ \\
Corestream LCA (gate) $^{1}$ & yes/no & $0 / 1$ \\
Downstream LCA $^{\text {(tomb) }}{ }^{1}$ & yes/no & $0 / 1$ \\
Carbon footprint $^{2}$ & yes/no & $0 / 0,5$ \\
\hline
\end{tabular}

1. Multiple impact categories considered for the assessment

2. Only greenhouse gasses emission (GWP) considered for the assessment

\subsubsection{Labels and declarations}

An entire section (Table 6) is dedicated to environmental communication systems. The more accurate the assessment, the higher the score. For products with more than one label and/or declaration of the same type, the score can be multiplied for the number of labels and/or declarations. All these parameters need to be proven with a valid certificate.

\subsubsection{Environmental impact categories}

This section is reserved only to manufacturers who requested an LCA, performed with the CLM method or have and EPD for their product. As previously explained this section has no score but is evaluated by weighting the impact categories with financial conversion factors (Table 1).

\subsubsection{Life cycle costing}

This section (Table 7) contains all the parameters that help to forecast the maintenance costs and other information that can be useful for the facility manager. 
Table 6. Labels and declarations parameters

\begin{tabular}{ccc}
\hline $\begin{array}{c}\text { Environmental labels and } \\
\text { declarations }\end{array}$ & Value type & Score \\
\hline Labels type I* & yes/no & $0 / 2$ \\
Labels type II* & yes/no & $0 / 1$ \\
Labels type III* & yes/no & $0 / 1$ \\
EPD (upstream) & yes/no & $0 / 1$ \\
EPD (corestream) & yes/no & $0 / 2$ \\
EPD (downstream) & yes/no & $0 / 3$ \\
Last EPD update & year & $0-3$ \\
\hline
\end{tabular}

Table 7. Life cycle costs parameters

\begin{tabular}{ccc}
\hline Life cycle costs & Value type & Score range \\
\hline Price & economic & - \\
Forecast lifetime & temporal & - \\
Ordinary maintenance frequency & temporal & - \\
Ordinary maintenance costs & economic & - \\
Extraordinary maintenance & temporal & - \\
frequency & economic & - \\
Extraordinary maintenance costs & temporal & $0-3$ \\
Delivery time & temporal & $0-3$ \\
Guarantee time* &
\end{tabular}

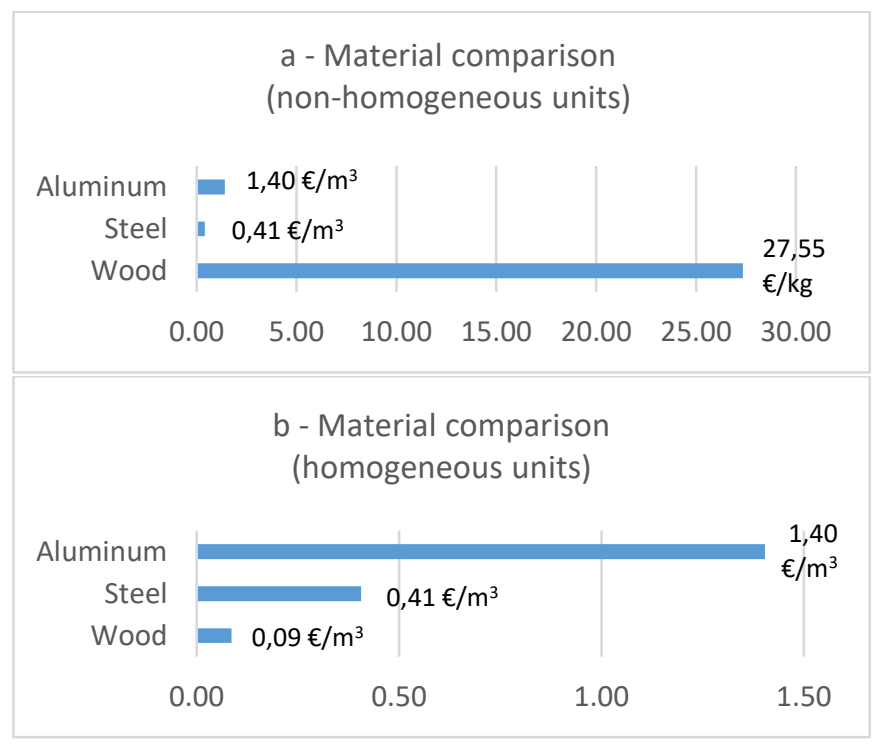

Figure 5. Results of material comparison

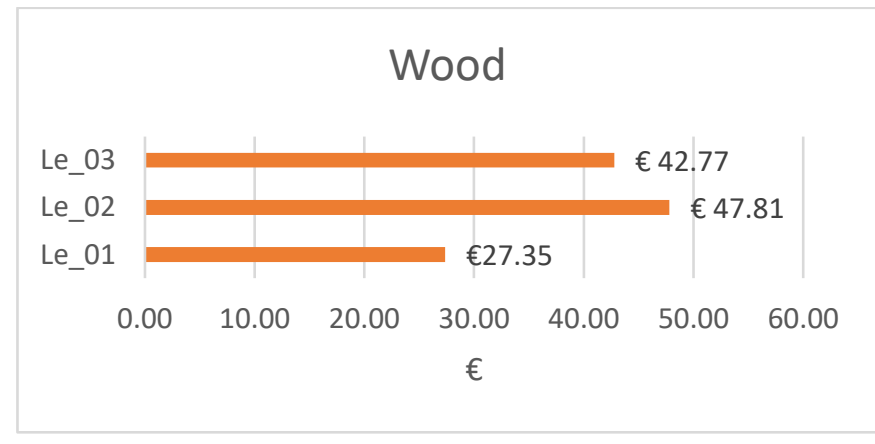

Figure 6. Results of wood products comparison

\subsection{Materials and products comparison}

To compare the environmental cost of steel, aluminum and wood, the environmental impacts of three products have been combined with the financial conversion factor previously presented in Table 1. The results are presented for each material as bar diagrams. The lower bar should represent the product with the lowest environmental cost impact. Since the environmental impacts of wood referred to a kilogram of product and the environmental impacts of steel and aluminum referred to a cubic meter of product, the environmental cost was not comparable, also because the specific gravity of the wood product was not declared (Figure 5a). To overcome this inconsistency issue, which prevent to compare the three products, it is reasonable to apply a conversion factor. The conversion factor transforms wood quantities from $\mathrm{kg}$ to $\mathrm{m}^{3}$. Based on ref. [33] we assumed a hypothetical value of $500 \mathrm{~kg}$ per $1 \mathrm{~m}^{3}$ of wood. Thus, the three environmental costs can be easily compared. The results show that wood has an environmental cost impact around ten times lower than aluminum and around four times lower than steel. The Assuming a hypothetical value for the specific weight (500 $\mathrm{kg} / \mathrm{m}^{3}$ ) for the wood product considered, the three environmental cost can be easily compared (Figure $5 \mathrm{~b}$ ).

However, since this conversion is based on theoretic values, to compare three real products, we decided to analyze three products for each type of materials. In this case the reference units are homogeneous for each material. For example, for outdoor wood the authors compared $1 \mathrm{~m}^{3}$ of laminated timber, transversally pre-stressed timber (Le_01), particle board (Le_02) and glued laminated timber (Le_03). The results (Figure 6) show that a laminated timber element which is transversally pre-stressed has the lowest environmental cost impact.

\section{DISCUSSION AND CONCLUSION}

In the building sector, BIM supports the optimization of processes and the information exchange between several disciplines. Therefore, a Building Information Model, including life cycle information, can support the optimization of environmental and economic performances of buildings. The developed evaluation system aims to optimize the procurement phase through digital tools and the application of automatic formulas and to highlight environmental and economic impacts during the life cycle, through the selected parameters. The benefits of such a system include: a reduced transaction time, an increased productivity, an improved transparency, an enhanced sustainability. There are several purposes connected with the selected parameters, such as:

- $\quad$ support eco-friendly production processes and valuechains,

- increase the awareness towards the environmental impact of buildings,

- promote labels and declarations for building construction materials,

- promote eco-innovation,

- encourage a more circular construction sector.

The expected advantages of this digital evaluation system for a public body are to consider a larger number of data during the procurement phase while spending limited time and resources on evaluating all received offers. Another advantage of this system is the generation, at the end of the evaluation process, of BIM objects completed with information useful for further phases e.g. O\&M and end of life. A possible weakness of this system is the need to check and compare the documents in attachment. In fact, a pre-set formula cannot evaluate qualitative information, such as labels and declarations. A possible improvement of the automatic evaluation could be the 
development of database of labels and declaration connected to a ranking system. The environmental cost, calculated through the financial conversion factor represents an opportunity to present, consider and compare environmental impacts also to those who does not have large experiences with LCA, as for example manufacturer or public bodies. Moreover, as shown by the results in 4.2, to compare the environmental cost of products made in different materials, it is crucial to have homogeneous reference units available.

Possible further implementations of the evaluation system could be:

- $\quad$ the introduction of energy parameters, as the energy mix of the production process,

- the definition of impact categories benchmarks and/or thresholds per materials,

- $\quad$ an operative test of the entire system.

\section{ACKNOWLEDGMENT}

The authors gratefully acknowledge ECAMRICERT who provided important information for the development of this research.

\section{REFERENCES}

[1] de Jong, M., Joss, S., Schraven, D., Zhan, C.J., Weijnen, M. (2015). Sustainable-smart-resilient-low carbon-ecoknowledge cities; making sense of a multitude of concepts promoting sustainable urbanization. Journal of Cleaner Production, 109: 25-38. https://doi.org/10.1016/j.jclepro.2015.02.004

[2] Pachuari, R.K., Meyer, L. (2014). Climate Change 2014 Synthesis Report. https://www.ipcc.ch/site/assets/uploads/2018/05/SYR_ AR5_FINAL_full_wcover.pdf, accessed on Oct. 28, 2020.

[3] Berardi, U. (2011). Sustainability assessment in the construction sector: Rating systems and rated buildings. Sustainable Development, 20(6): 411-424. https://doi.org/10.1002/sd.532

[4] Emami, N., Heinonen, J., Marteisson, B., Säynäjoki, A. Junnonen, J.M., Laine, J., Junnila, S. (2019). A life cycle assessment of two residential buildings using two different LCA database-software combinations: Recognising uniformities and inconsistencies. Buildings, 10(5): 90. https://doi.org/10.3390/buildings10050090

[5] Bolpagni, M. (2012). The implementation of BIM within the public procurement. VTT Technology, 130: 233.

[6] Eleftheriadis, S., Mumovic, D., Greening, P. (2017). Life cycle energy efficiency in building structures: A review of current developments and future outlooks based on BIM capabilities. Renewable and Sustainable Energy Reviews 67:

$811-825$ https://doi.org/10.1016/j.rser.2016.09.028

[7] Villac, T., dos Santos, M.C.L. (2020). Sustainable public procurement in Brazil. Sustainable Consumption, Springer, Cham. https://doi.org/10.1007/978-3-03016985-5_7

[8] Kreiner, H., Scherz, M., Passer, A. (2018). How to make decision- makers aware of sustainable construction? In R. Caspeele, L. Taerwe, \& D. Frangopol (Eds.), Life-Cycle
Analysis and Assessment in Civil Engineering: Towards an Integrated Vision, London.

[9] Soust-Verdaguer, B., Llatas, C., García-Martínez, A. (2017). Critical review of bim-based LCA method to buildings. Energy and Buildings, 136: 110-120. https://doi.org/10.1016/j.enbuild.2016.12.009

[10] Barbini, A., Malacarne, G., Massari, G., Pasetti Monnizza, G., Matt, D.T. (2019). BIM object library for information exchange in public works: The use of proprietary and open formats. WIT Transactions on the Built Environment, 192: 269-280. https://doi.org/10.2495/bim190231

[11] Baldo, G.L., Marino, M., Rossi, S. (2008). Analisi del ciclo di vita LCA, Gli strumenti per la progettazione sostenibile di materiali, prodotti e processi, Edizione Ambiente, Cerbara-Perugia, Italy.

[12] Meex, E., Hollberg, A., Knapen, E., Hildebrand, L., Verbeeck, G. (2018). Requirements for applying LCAbased environmental impact assessment tools in the early stages of building design. Building and Environment, 133: 228-236. https://doi.org/10.1016/j.buildenv.2018.02.016

[13] Asdrubali, F., Baldassarri, C., Fthenakis, V. (2013). Life cycle analysis in the construction sector: Guiding the optimization of conventional Italian buildings. Energy and Buildings, 64: 73-89. https://doi.org/10.1016/j.enbuild.2013.04.018

[14] Buyle, M., Braet, J., Audenaert, A. (2013). Life cycle assessment in the construction sector: A review. Renewable and Sustainable Energy Reviews, 26: 379388. https://doi.org/10.1016/j.rser.2013.05.001

[15] Sartori, I., Hestnes, A.G. (2007). Energy use in the life cycle of conventional and low-energy buildings: A review article. Energy and Buildings, 39(3): 249-257. https://doi.org/10.1016/j.enbuild.2006.07.001

[16] Ortiz-Rodriguez, O., Colodel, C., Fischer, M., Castells, F., Sonnemann, G. (2010). An application of life cycle assessment (LCA) within the Catalonian building sector: A case study. Afinidad, 67: 262-267.

[17] Röck, M., Hollberg, A., Habert, G., Passer, A. (2018). LCA and BIM: Integrated assessment and visualization of building elements' embodied impacts for design guidance in early stages. Procedia CIRP, 69: 218-223. https://doi.org/10.1016/j.procir.2017.11.087

[18] Najjar, M., Naves, A.X., Figueiredo, K., Boer, D. (2017). Evaluation of environmental impacts of building materials in the construction sector integrating BIM and LCA. International Congress Engineering, ICEUBI 2017, Portugal 2017, pp. 970-977.

[19] Santos, R., Costa, A.A., Silvestre, J.D., Pyl, L. (2019). Integration of LCA and LCC analysis within BIM-based environment. Automation in Construction, 103: 127-149. https://doi.org/10.1016/j.autcon.2019.02.011

[20] Hellweg, S., Doka, G., Finnveden, G., Hungerbühler, K. (2005). Assessing the eco-efficiency of end-of-pipe technologies with the environmental cost efficiency indicator. Journal of industrial Ecology, 9(4): 189-203. https://doi.org/10.1162/108819805775247864

[21] Lehni, M., WBCSD. (2000). Ecoefficiency: Creating more value with less impact. World Business Council for Sustainable Development Conches-Geneva, Switzerland.

[22] Parikka-Alhola, K. (2008). Promoting environmentally sound furniture by Green Public Procurement. 
Ecological Economics, 68(1-2): 472-485. https://doi.org/10.1016/j.ecolecon.2008.05.004

[23] European Commission. Environment, GPP Criteria, Background and approach. https://ec.europa.eu/environment/gpp/gpp_criteria_en.ht m, accessed on Jan. 24, 2020.

[24] van Harmelen, A.K., Broers, J.W., Duijsens, L.J.E., Korenromp, R.H.J., Ligthart, T.N. (2004). Toxiciteit heeft z'n prijs: schaduwprijzen voor (eco-)toxiciteit en uitputting van abiotische grondstoffen binnen DuboCalc bijlagen, TNO, Milieu, Energie en Procesinnovatie (TNO-MEP), Delft, $\quad$ p. 8. http://publicaties.minienm.nl/documenten/toxiciteitheeft-z-n-prijs-schaduwprijzen-voor-eco-toxiciteit-en, accessed on Jan. 24, 2020.

[25] OVAM, https://www.vlaanderen.be/publicaties/annexmonetisation-of-the-mmg-method-update-2017.

[26] Accessed on: 24 Jan. 2020. GBC Italia. LEED v4 for BUILDING DESIGN AND CONSTRUCTION, Italian Translation, Update 08 November 2016, pp. 80-90. https://www.usgbc.org/sites/default/files/LEED-v4BDC-Italian_0.pdf, accessed on Oct. 28, 2020.

[27] DGNB criteria. Sustainable resource extraction, DGNB. https://www.dgnbsystem.de/en/system/version2018/criteria/sustainableresource-extraction/, accessed on Jan. 24, 2020.

[28] Regolamento tecnico nuove costruzioni - versione breve; Documenti tecnici, https://www.arcacert.com/documenti-tecnici/, accessed on Jan. 24, 2020.

[29] Olivieri, G., Neri, P., Romani, A. Analisi ambientale ed economica del riciclo dell'alluminio con il metodo LCA, Progetto SPINNER c/o ENEA. http://www.dichep.unige.it/old_site/ge2004/poster/Olivi eri_Neri_Romani_LCAge04.pdf, accessed on Oct. 28, 2020 .

[30] Gautam, M., Pandey, B., Agrawal, M. (2018). Chapter 8 - carbon footprint of aluminum production: Emissions and mitigation. Environmental Carbon Footprints Industrial Case Studies, 226-228. https://doi.org/10.1016/B978-0-12-812849-7.00008-8

[31] Methodology for the free allocation of emission allowances in the EU ETS post 2012, Sector report for the aluminium industry. https://ec.europa.eu/clima/sites/clima/files/ets/allowance s/docs/bm_study-aluminium_en.pdf, accessed on Jan. 24, 2020.

[32] Brilhuis-Meijer, E. (2020). Weighting: Applying a value judgement to LCA result. https://www.presustainability.com/news/weighting-applying-a-valuejudgement-to-lca-results, accessed on Jan. 24, 2020.

[33] Wood gravity weight. http://www.ediltool.com/main/tabelle-deimateriali/peso-specifico-legno/, accessed on Aug. 28, 2020. 